7 ISIS-3 (Third International Study of Infarct Survival) Collaborative Group. ISIS-3: A randomised trial of streptokinase vs tissue plasminogen activator vs anistreplase and of aspirin plus heparin vs aspirin alone among 41,299 cases of suspected acute myocardial infarction. Lancet 1992;339:753-70.

8 EMERAS (Estudio Multicéntrico Estreptoquinasa Repúblicas de América del Sur) Collaborative Group. Randomised trial of late thrombolysis in patients with suspected acute myocardial infarction. Lancet 1993;342:767-72.

9 LATE Study Group. Late assessment of thrombolytic efficacy (LATE) study with alteplase 6-24 hours after onset of acute myocardial infarction. Lancet 1993;342:759-66.

10 Fibrinolytic Therapy Trialists' Collaborative Group. Indications for fibrinolytic therapy in suspected acute myocardial infarction: collaborative overview of early mortality and major morbidity results from all randomised trials of more than 1000 patients. Lancet 1994;343:311-22.

11 Gruppo Italiano per lo Studio della Streptochinasi nell'Infarto miocardico (GISSI). Long-term effects of intravenous thrombolysis: final report of the GISSI study. Lancet 1987;ii:871-4.

12 Schröder R, Neuhaus K-L, Leizorovicz A, Linderer T, Tebbe U for the ISAM Study Group. A prospective placebo-controlled double-blind multicenter trial of intravenous streptokinase in acute myocardial infarction (ISAM) long-term mortality and morbidity. J Am Coll Cardiol 1987;9:197-203.

13 Wilcox RG, von der Lippe G, Olsson CG, Jensen G, Skene AM, Hampton JR for the Anglo-Scandinavian Study of Early Thrombolysis. Effects of alteplase in acute myocardial infarction: 6-month results from the ASSET study. Lancet 1990;335:1175-8.

14 Hillis WS, Chamberlain DA, de Bono DP, Fox KAA, Murray RG, Julian DG, et al for the AIMS Study Group. Intravenous anistreplase in acute myocardial infarction: continued reduction in mortality up to 5 years: long-term results of the AIMS study [abstract]. Eur Heart J 1992; 13(suppl):305

15 Simoons ML, Vos J, Tijssen JGP, Vermeer F, Verheugt FWA, Krauss XH, et al. Long-term benefit of early thrombolytic therapy in patients with acute myocardial infarction: 5-year follow-up of a trial conducted by the Interuniversity Cardiology Institute of the Netherlands. J Am Coll Cardiol 1989;14:1609-15.

16 Cerqueira MD, Maynard C, Ritchie JL, Davis KB, Kennedy JW. Long-term survival in 618 patients from the Western Washington streptokinase in myocardial infarction trials. J Am Coll Cardiol 1992;20:1452-9.

17 Lenderink T, Simoons ML, Van Es G-A, Van de Werf F, Verstraete M, Arnold AER for the European Cooperative Study Group. Benefit of thrombolytic therapy is sustained throughout five years and is related to TIMI perfusion grade 3 but not grade 2 flow at discharge. Circulation $1995 ; 92: 1110-6$

18 Van de Werf F. Thrombolysis for acute myocardial infarction: why is there no extra benefit after hospital discharge? Circulation 1995;91:2862-4.

19 White HD. Thrombolytic therapy for patients with myocardial infarction presenting after 6 hours. Lancet 1992;340:221-2.
20 Rawles J. Magnitude of benefit from earlier thrombolytic treatment in acute myocardial infarction: new evidence from Grampian region early anistreplase trial (GREAT). BMJ 1996;312:212-6.

21 White SJ, Freedman LS. Allocation of patients to treatment groups in a controlled clinical study. Br J Cancer 1978;37:849-57.

22 Peto R, Pike MC, Armitage P, Breslow NE, Cox DR, Howard SV, et al. Design and analysis of randomised clinical trials requiring prolonged observation of each patient. Part II: Analysis and examples. Br J Cancer 1977;35:1-39.

23 White HD, Cross DB, Eiliot JM, Norris RM, Yee TW. Long-term prognostic importance of patency of the infarct-related coronary artery after thrombolytic therapy for acute myocardial infarction. Circulation 1994;89:61-7.

24 Lamas GA, Flaker GC, Mitchell G, Smith SC, Gersh BJ, Wun C-C, et al for the Survival and Ventricular Enlargement Investigators. Effect of infarct artery patency on prognosis after acute myocardial infarction. Circulation 1995;92:1101-9.

25 Granger CB, White HD, Bates ER, Ohman EM, Califf RM. A pooled analysis of coronary artery patency and left ventricular function after intravenous thrombolysis for acute myocardial infarction. Am J Cardio 1994;74:1220-8

26 Harrison JK, Califf RM, Woodlief LH, Kereiakes D, George BS, Stack RS, et al for the TAMI Study Group. Systolic left ventricular function after reperfusion therapy for acute myocardial infarction. An analysis of determinants of improvement. Circulation 1993;87:1531-41.

27 Volpi A, De Vita C, Franzosi MG, Geraci E, Maggioni AP, Mauri F, et al for the Ad Hoc Working Group of the Gruppo Italiano per lo Studio della Soprovvivenza nell'Infarto miocardico (GISSI)-2 data base. Determinants of 6-month mortality in survivors of myocardial infarction after

28 Gurwitz JH, Goldberg RJ, Gore JM. Coronary thrombolysis for the elderly? JAMA 1991;265:1720-3.

29 European Secondary Prevention Study Group. Translation of clinical trials into practice: a European population-based study of the use of thrombolysis for acute myocardial infarction. Lancet 1996;347:1203-7.

30 Rogers WJ, Bowlby LJ, Chandra NC, French WJ, Gore JM, Lambrew CT, et al for the Participants in the National Registry of Myocardial Infar the Partip of to 1993). Observations from the National Registry of Myocardial Infarction. Circulation 1994;90:2103-14.

31 Gurwitz JH, Gore JM, Goldberg RJ, Rubison M, Chandra N, Rogers WJ for the Participants in the National Registry of Myocardial Infarction. Recent age-related trends in the use of thrombolytic therapy in patients who have had acute myocardial infarction. Ann Intern Med 1996;124:283-91.

32 Antiplatelet Trialists' Collaboration. Collaborative overview of randomised trials of antiplatelet therapy. I: Prevention of death, myocardial infarction, and stroke by prolonged antiplatelet therapy in various categories of patients. BMJ 1994;308:81-106.

(Accepted 2 February 1998)

\title{
Fetal and maternal contributions to risk of pre-eclampsia: population based study
}

\author{
Rolv Terje Lie, Svein Rasmussen, Helge Brunborg, Håkon K Gjessing, Erik Lie-Nielsen, \\ Lorentz M Irgens
}

\begin{abstract}
Objective: To use familial patterns of recurrence of pre-eclampsia to investigate whether paternal genes expressed in the fetus contribute to the mother's risk of pre-eclampsia and whether mother's susceptibility to pre-eclampsia is related to maternal inheritance by mitochondrial DNA.

Design: Linked data on pregnancies of different women who had children with the same father, and subsequently linked data on pregnancies of half sisters who either had same mother and different fathers or had same father and different mothers.

Setting: Population based data from the Medical Birth Registry of Norway covering all births since 1967

(about 1.7 million) and the Norwegian Central

Population Register.

Main outcome measures: Relative risk of pre-eclampsia after a previous pre-eclamptic pregnancy in the family. Relative risks approximated by odds ratios.
\end{abstract}

Results: If a woman becomes pregnant by a man who has already fathered a pre-eclamptic pregnancy in a different woman her risk of developing pre-eclampsia is 1.8 (95\% confidence interval 1.2 to 2.6$)$. If the woman has a half sister who had pre-eclampsia and with whom she shares the same mother but different fathers the risk of pre-eclampsia is 1.6 (0.9 to2.6). If the two sisters have the same father but different mothers the risk is 1.8 (1.01 to 2.9).

Conclusions: Both the mother and the fetus contribute to the risk of pre-eclampsia, the contribution of the fetus being affected by paternal genes. Mitochondrial genes, which are transmitted by mothers, do not seem to contribute to the risk.

\section{Introduction}

Pre-eclampsia is a life threatening complication of pregnancy characterised by high blood pressure and proteinuria $^{1}$; it occurs in about $3 \%$ of all pregnancies. ${ }^{2}$ 
Medical Birth Registry of Norway, Armauer Hansen's Building,

Haukeland

Hospital, 5021

Bergen

Svein Rasmussen,

obstetrician

Erik Lie-Nielsen, managing director

Lorentz M Irgens, professor

Statistics Norway, PO Box 8131 Dep, 0033 Oslo, Norway Helge Brunborg, researcher

Correspondence to: Professor Lie rolv.lie@smis.uib.no
The aetiology of pre-eclampsia is still obscure, despite many attempts to identify possible causes.

Theoretically, both mother and fetus may contribute to the risk. Pre-eclampsia may reflect problems in the close biological interaction between the two subjects. ${ }^{3}$ Early stages in the development of preeclampsia may be related to poor placental perfusion, ${ }^{4}$ possibly due to incomplete invasion of fetal trophoblast cells into the uterus and maternal resistance against such invasion. Maternal symptoms like hypertension and proteinuria may reflect the later stages of fetal and maternal strategies to compensate for poor perfusion. Current knowledge on the epidemiology of pre-eclampsia, like the particularly high risk in first pregnancies, points primarily to an effect of maternal factors. ${ }^{56}$

An immunological model for pre-eclampsia has been suggested, and studies indicate that a previous pregnancy with the same father and a longer period of sexual cohabitation with the father before conception reduces the risk. ${ }^{6}{ }^{7}$ One interpretation is that a mother adapts to imprinted antigens from the father.

A substantial risk of recurrence and a tendency of familial clustering of pre-eclampsia is well documented. ${ }^{8}$ Several models of inheritance have been proposed, ${ }^{10-12}$ and specific candidate genes that may account for maternal susceptibility have been identified. ${ }^{13}{ }^{14}$ Recently it was suggested that genetic susceptibility to pre-eclampsia was partly due to maternal inheritance by mitochondrial genes. ${ }^{15}$

We hypothesised that pre-eclampsia is initiated in part by the fetus and in part by maternal susceptibility. Specifically we attempted to identify any contribution from paternal genes in the fetus. We used population based family data from the Medical Birth Registry of Norway and the Central Population Register of Norway to assess these contributions. We also attempted to quantify any contribution to susceptibility from mitochondrial genes, which are transmitted only through the mother.

\section{Subjects and methods}

The Medical Birth Registry of Norway comprises all births in Norway since 1967 with more than 16 weeks of completed gestation (about 60000 births a year). Births up till 1992 were included in this study. For all births the national identification number was recorded for mother and child. Father's identification was missing for $8 \%$ of the births.

Pre-eclampsia is usually recorded by the registry as a specified diagnosis. The medical birth registration form may also hold information about specific symptoms of pre-eclampsia, such as hypertension, proteinuria, or oedema during pregnancy. Our case definition included all pregnancies with a specified diagnosis of pre-eclampsia and pregnancies recorded with both pregnancy related hypertension and proteinuria.

\section{Record linkage}

By internal record linkage with the national identification numbers of mothers and fathers in the birth registry we identified 363758 pairs of first and second pregnancies when the two children had the same mother and father; 14266 pairs of pregnancies when the children had the same mother but different fathers; and 26152 pairs of pregnancies where the children had the same father but different mothers. The reported number of children with either same mother and different fathers or same father but different mothers may be too low because the father of one or both children may not have been recorded.

Firstly, we assessed the proposed immunological hypothesis that several pregnancies with the same father reduce the risk by comparing the risk in second pregnancies of mothers who had the same partner with risk in mothers who changed partner after their first pregnancy. We then studied the risk of recurrence of pre-eclampsia among mothers who had a second pregnancy with the same partner, mothers who had their second pregnancy with a new partner, and mothers whose second pregnancy was fathered by a man who had also fathered a pre-eclamptic pregnancy in another woman.

\section{Analysis}

The relative risk of recurrence of pre-eclampsia in a second pregnancy was used to measure the degree of association between pregnancies. These relative risks were estimated by odds ratios. ${ }^{16}$ The statistical analyses were based on logistic regression techniques, ${ }^{17}$ considering the risk of pre-eclampsia in the second pregnancies as the outcome and pre-eclampsia in the first pregnancy as a covariate, eliminating the effect of parity. We also adjusted for the potential confounding of mother's age and time interval between pregnancies and estimated the effect of calendar time to test for possible changes in diagnosis of preeclampsia over time.

Next, we linked the birth registry with the population register, which contains identification numbers of parents of everyone born in Norway after 1952. We used this linkage to identify pairs of mothers in the birth registry who were sisters. Only mothers whose first pregnancy was recorded by the registry were included. Altogether, 61186 pairs of mothers had same parents. These full sisters served as the reference group. In total 3766 pairs of mothers were half sisters with same mother but different fathers (maternal half sisters) and 4290 pairs were half sisters with same father but different mothers (paternal half sisters).

The odds ratio was again used to measure the degree of association between the risk of the two sisters for pre-eclampsia. Instead of considering only pairs of first and second pregnancies, pairs of any first three pregnancies from two sisters were considered to increase the sample size. To compute a pooled odds ratio for this association we paired all pregnancies for a mother with all pregnancies of her sister. Thus, if a mother $\mathrm{A}$ had $\mathrm{a}_{\mathrm{A}}$ pregnancies with $\mathrm{b}_{\mathrm{A}}$ cases of pre-eclampsia and her sister $B$ had $\mathrm{a}_{\mathrm{B}}$ pregnancies with $\mathrm{b}_{\mathrm{B}}$ cases of pre-eclampsia, this pair of sisters contributed $\left(a_{A}-b_{A}\right)\left(a_{B}-b_{B}\right),\left(a_{A}-b_{A}\right) b_{B}, b_{A}\left(a_{B}-b_{B}\right)$, and $b_{A} b_{B}$ pairs of the types $(0,0),(0,1),(1,0)$, and $(1,1)$, respectively, to the computation of the pooled odds ratio. Here, 0 denotes a pregnancy without preeclampsia and 1 a pregnancy with pre-eclampsia. We then joined these $a_{A} a_{B}$ pairs with the corresponding pairs from all sister units in a formula for the odds ratio that does not distinguish between pairs of the type $(0,1)$ 
and the type $(1,0)$ as the sequence of the mothers $\mathrm{A}$ and $\mathrm{B}$ is arbitrary. ${ }^{18}$ When we computed confidence intervals for the odds ratio we accounted for the statistical dependence between the $\mathrm{a}_{\mathrm{A}} \mathrm{a}_{\mathrm{B}}$ pairs arising from the same pair of mothers by using a Monte Carlo resampling technique. This strategy gives wider and more correct confidence limits compared with an analysis of all pairs of pregnancies that ignores the dependency.

\section{Results}

The strong effect of parity on risk of pre-eclampsia was confirmed in our data (table 1). In first pregnancies the risk was above $3 \%$, slightly increasing with mother's age. The risk was $1.7 \%$ among second pregnancies in mothers who had their second pregnancy with the same partner and $1.9 \%$ among second pregnancies in mothers who had changed their partner since the first pregnancy. This small tendency of increased risk in second pregnancy when the mother changed partner was highly significant, even after adjustment for maternal age and calendar year $(\mathrm{P}<0.001)$.

Mothers who had pre-eclampsia in the first pregnancy also had a high risk in their next pregnancy. The risk was $13.1 \%$ if she had her second pregnancy with the same partner but dropped to $11.8 \%$ if she changed the partner $(\mathrm{P}=0.12$ for difference) (table 2$)$. Mothers without pre-eclampsia in the first pregnancy had a slightly increased risk in the second if they changed partner $(1.6 \% v 1.3 \%, \mathrm{P}=0.03)$. Mothers had a substantially increased risk in their second pregnancy $(2.9 \%)$ if they became pregnant by a man who had fathered a pre-eclamptic first pregnancy in another woman. This risk was nearly as high as the average risk among first pregnancies.

These absolute risks may also be expressed as relative risks. Mothers with pre-eclampsia in their first pregnancy were nearly 12 times more likely than other mothers to have pre-eclampsia in their second pregnancy (odds ratio 11.8; 95\% confidence interval
11.1 to 12.6). If these women changed partners for their second pregnancy their risk of recurrence was reduced but still substantial $(8.2 ; 5.9$ to 11.3$)$, although not significant $(\mathrm{P}=0.18)$. Some risk of recurrence was, however, transmitted by the father. Men who fathered one pre-eclamptic pregnancy were nearly twice as likely to father a pre-eclamptic pregnancy in a different woman (1.8; 1.2 to 2.6; after adjustment for parity), regardless of whether she had already had a pre-eclamptic pregnancy or not.

Maternal age, calendar time, and time between pregnancies may confound these risks of recurrence so we used logistic regression models to adjust for these factors. The risk of pre-eclampsia in a second pregnancy increased with maternal age ( 1.3 per 5 years of increased age; $\mathrm{P}<0.0001)$ and with interval between pregnancies $(1.5$ per 5 years of increased interval between first and second pregnancy; $\mathrm{P}<0.0001$ ). Calendar time had no significant effect. The estimated risks of recurrence for mothers with the same partners and mothers with different partners were, however, only marginally affected by the adjustment (11.7 and 9.0 , respectively). A change in residential municipality was also entered into this model but had no effect on risks of recurrence of pre-eclampsia $(\mathrm{P}=0.91)$.

A similar model was used to adjust for maternal age and calendar year when we compared pairs of pregnancies of same mother with different fathers and pregnancies of different mothers with the same father. Maternal age had a similar effect in this analysis, and calendar year of the birth was insignificant. Again, the odds ratios of recurrence were only marginally affected by the adjustment ( 8.8 for pregnancies of same mother with different fathers and 2.0 for pregnancies of different mothers with same father).

Finally, we estimated the association of risks between pairs of mothers who were either full sisters, half sisters with same mother but different fathers (maternal half sisters), or half sisters with same father but different mothers (paternal half sisters) (table 3). The estimated odds ratio was highest for full sisters

Table 1 Total risk of pre-eclampsia in first and second pregnancy for mothers who had two pregnancies with same father and mothers who had two pregnancies with different fathers. Data from Medical Birth Registry of Norway, 1967-92

\begin{tabular}{lccccccc} 
& & \multicolumn{2}{c}{ Mother's 1st pregnancy } & & \multicolumn{2}{c}{ Mother's 2nd pregnancy } \\
\cline { 3 - 4 } \cline { 6 - 8 } Detail & No of pregnancies & Risk (\%) & $\begin{array}{c}\text { Mean (SD) age of mother } \\
\text { (years) }\end{array}$ & & \multicolumn{2}{c}{$\begin{array}{c}\text { Mean (SD) age of mother } \\
\text { (years) }\end{array}$} \\
\hline Pregnancies with same father & 363758 & 3.4 & $24.0(3.8)$ & & 1.7 & $27.2(4.1)$ \\
\hline Pregnancies with different fathers & 14266 & 3.0 & $21.7(3.3)$ & & 1.9 & $28.5(4.7)$ \\
\hline
\end{tabular}

Table 2 Risk of recurrence of pre-eclampsia in mother's second pregnancy considering her own previous pregnancy or another woman's pregnancy with same father. Data from Medical Birth Registry of Norway, 1967-92

\begin{tabular}{|c|c|c|c|c|c|}
\hline Pre-eclampsia in 1st pregnancy & No at risk & $\begin{array}{c}\text { No of cases of } \\
\text { pre-eclampsia in 2nd } \\
\text { pregnancy }\end{array}$ & Risk (\%) & Unadjusted odds ratio $(95 \% \mathrm{CI})$ & $P$ value ${ }^{*}$ \\
\hline \multicolumn{6}{|l|}{ Same mother and same father } \\
\hline Yes & 12437 & 1635 & 13.1 & \multirow{2}{*}{11.8 (11.1 to 12.6$)$} & \multirow{2}{*}{$<0.0001$} \\
\hline No & 351321 & 4443 & 1.3 & & \\
\hline \multicolumn{6}{|l|}{ Same mother and different fathers } \\
\hline Yes & 432 & 51 & 11.8 & \multirow{2}{*}{8.2 (5.9 to 11.3$)$} & \multirow{2}{*}{$<0.0001$} \\
\hline No & 13834 & 223 & 1.6 & & \\
\hline \multicolumn{6}{|l|}{ Different mothers and same father } \\
\hline Yes & 989 & 29 & 2.9 & \multirow{2}{*}{$1.8(1.2$ to 2.6$)$} & \multirow{2}{*}{0.005} \\
\hline No & 25163 & 418 & 1.7 & & \\
\hline
\end{tabular}

*Exact two sided $\mathrm{P}$ value testing difference of odds ratio from 1. 
Table 3 Risk of recurrence of pre-eclampsia between mothers who are sisters. Data from Medical Birth Registry of Norway, 1967-92, and Central Population Register of Norway

\begin{tabular}{lcc} 
Relationship between mothers & No of pregnancies & Odds ratio (95\% $\mathbf{~ I ) ~}$ \\
\hline Full sisters & 61186 & $2.2(1.9$ to 2.5$)$ \\
\hline Maternal half sisters $\dagger$ & 3766 & $1.6(0.9$ to 2.6$)$ \\
\hline Paternal half sisters $\ddagger$ & 4290 & 1.8 (1.01 to 2.9) \\
\hline
\end{tabular}

${ }^{*}$ Sisters with same mother and father.

tHalf sisters with same mother but different fathers.

$\ddagger$ Half sisters with same father but different mothers.

and lowest for maternal half sisters (2.2 $v$ 1.6). For paternal half sisters the odds ratio was 1.8. None of the differences between these odds ratios reached significance.

\section{Discussion}

This study shows a high risk of recurrence of pre-eclampsia among women who had pre-eclampsia in an earlier pregnancy, confirming estimates provided by previous studies. ${ }^{9}$ Our data, however, also strongly suggest that paternal genes (as expressed in the fetus) contribute to the mother's risk of pre-eclampsia. Mothers who were pregnant by a partner who fathered a pre-eclamptic pregnancy in another woman had nearly twice the risk in their own pregnancy. Alternative but less likely explanations are persistent environmental exposures or infections transmitted by the man.

\section{Contribution of fetal genes}

The total effect of genes in the fetus on mother's risk of pre-eclampsia is probably larger than the effect of genes from the father because maternal genes in the fetus may also contribute. Genomic imprinting or specific immunological mechanisms that distinguish between maternal and paternal influence may result in maternal genes in the fetus having a different effect from paternal genes.

Our data do not allow a direct comparison of the contribution to the risk of genes in the mother and genes in the fetus. They do, however, provide estimates of risks of recurrence between unrelated mothers whose fetuses are paternal half siblings (odds ratio 1.9) and risks of recurrence between mothers who are half sisters (1.6 and 1.8, respectively, for maternal and paternal half sisters). Given that the risk of recurrence carried by related fetuses is as high as the risk of recurrence for related mothers, the fetus's contribution to risk may be as large as the mother's own contribution.

\section{Contribution of father's genes}

Our results are compatible with a recently published model in mice showing that both renin genes from the father and angiotensinogen II genes in the mother may contribute to the risk of hypertension during pregnancy. ${ }^{19}$

A strong total increase in risk of pre-eclampsia among mothers who changed partners, regardless of pre-eclampsia in a previous pregnancy, has been reported by others. ${ }^{6} 7$ This increase was only marginal in our data but still significant. A general immunological mechanism that responds to a new father by increasing the risk of pre-eclampsia may be existent but is not very strong.
We found, however, a slight decrease in risk of recurrence of pre-eclampsia in mothers who changed partners. This decrease may be the combined effect of two mechanisms working in opposite directions. Replacement of the father after a pre-eclamptic pregnancy should on the one hand remove the previous father's genetic contribution to the risk but on the other hand introduction of a new father could trigger an immunological response in the mother that may cause pre-eclampsia.

\section{Contribution of mitochondrial genes}

Structural and genetic changes in mitochondria have been reported in patients with pre-eclampsia. ${ }^{1520}$ If maternal susceptibility was entirely attributable to mitochondrial genes, women who have same father but different mothers (paternal half sisters) should share no risk because their mitochondrial DNA is unrelated. Our data indicate that there is still some shared risk among paternal half sisters. This is consistent with a smaller study from Iceland, ${ }^{11}$ which found that the association between risk of pre-eclampsia in

What causes pre-eclampsia?

Pre-eclampsia is a common condition, but little is known about its cause. There is definitely a genetic component, but studies of twins indicate that there is more to pre-eclampsia than genes alone. The placenta is thought to be the prime suspect, which is why delivery of the placenta guarantees resolution of the syndrome.

Bloodborne factors-which may include lipid peroxides, fatty acids, cytokines, and microvesicles from the trophoblast itself-are probably shed from the surface of the placenta and then enter the maternal circulation. Maternal endothelial cells are activated by these factors, and all the features of pre-eclampsia can be explained by the circulatory disturbance which follows.

Hypertension results from vasoconstriction, oedema is the consequence of increased vascular permeability, and proteinuria is probably caused by dysfunction of endothelial cells in the glomeruli.

Some researchers believe that placental hypoxia-caused by spiral arterial disease-leads to the shedding of factors from the placenta. Such a degree of hypoxia would be caused by obstruction of the arteries or poor adaptation of the arteries to the needs of pregnancy.

As placentation and the laying down of the spiral arteries occurs in the first half of pregnancy the pathological process behind pre-eclampsia looks as if it gets going long before the clinical syndrome becomes apparent. The control of placentation may well have an immunological basis-with an interaction occurring between maternal and fetal genes. This could explain why women are more at risk of pre-eclampsia in their first pregnancy and why parous women who later conceive by a new partner also have an increased susceptibility to the syndrome. 
grandmothers and granddaughters was independent of whether the connection was through the grandmother's son or daughter. This evidence makes it unlikely that inherited mitochondrial genes play a major part in the aetiology of pre-eclampsia.

\section{Possible biases and confounding}

Our data covered all births occurring in Norway between 1967 and 1992. There was no effect of year of birth that could confound our results nor any effect of change in residence. The absence of an effect on risk of change in residence suggests that estimates of risk of pre-eclampsia are neither strongly affected by environmental factors nor by regional differences in diagnosis and reporting. ${ }^{17}$ We used well accepted criteria of preeclampsia, and apparently the reporting was consistent throughout the whole period. Even though we adjusted for maternal age there is still potential for confounding and bias by other factors. Different unknown social and biological factors may act in families of half siblings and other families.

Overall, $8 \%$ of the birth records contained no information on the father. Missing paternity information is probably less common among stable couples. We have therefore probably ascertained a lower proportion of pairs of pregnancies with same mother and different fathers or same father and different mothers compared with pairs of pregnancies of same father and mother. Any bias due to this incomplete ascertainment is, however, not likely.

Estimates of the proportion of children with wrong paternity information vary considerably. ${ }^{21}$ The frequently mentioned estimate of $10 \%$ may be lower in the Norwegian population. Our main findings-the association between pregnancies of unrelated mothers who became pregnant with the same man and the association between pregnancies of half sisters who had the same recorded father but different mothersmay be even stronger if there were errors in the paternity information. Some of the units that are included in the analyses of paternal half siblings would in fact be unrelated. The weak association estimated for maternal half sisters, on the other hand, may be an overestimate because some of the sisters may also have the same father. Overall, our results are strengthened by the possibility of errors in the information on paternity.

The complicated aetiology of pre-eclampsia calls for studies that appreciate the contribution from both the mother and the fetus. Our study gives evidence for a non-mitochondrial maternal genetic component as well as an equally strong fetal component related to paternal genetic influence.

We thank Dr Allen Wilcox and Professor Stein Emil Vollset for constructive comments and suggestions.

Contributors: RTL had the original idea, carried out most of the analyses, and drafted and edited the paper. SR had responsibility for clinical aspects and contributed to the writing. HB contributed to the planning and discussion of record linkage to identify mothers who were sisters and to the writing of the paper. HKG was responsible for the analysis comparing multiple pregnancies of sisters and for the description of the method of that analysis. ELN was responsible for all record linkage in the paper. LMI contributed to the initial discussions of design, interpretation of results, and writing of the paper. RTL is guarantor of the paper.

Funding: None.

Conflict of interest: None.
Key messages

- Paternal genes in the fetus may contribute substantially to a pregnant woman's risk of pre-eclampsia

- The role of the fetus may be as important as that of the mother

- Purely maternal inheritance (specifically by mitochondrial DNA) is probably not involved in pre-eclampsia

- Search for specific genes that predispose for pre-eclampsia should include the fetus as well as the mother

1 Loudon I. Some historical aspects of toxaemia of pregnancy. A review. $\mathrm{Br}$ J Obstet Gynaecol 1991;98:853-8.

2 Saftlas AF, Olson DR, Franks AL, Atrash HK, Pokras R. Epidemiology of pre-eclampsia and eclampsia in the United States, 1979-1986. Am J Obstet Gynecol 1990;163:460-5.

3 Haig D. Genetic conflicts in human pregnancy. Q Rev Biol 1993;68: 495-532.

4 Vinatier D, Monnier JC. Pre-eclampsia: physiology and immunological aspects. Eur J Obstet Gynecol Reprod Biol 1995;61:85-97.

5 MacGillivray I. Some observations on the incidence of pre-eclampsia. J Obstet Gynaecol Br Emp 1958;65:536-9.

6 Trupin LS, Simon LP, Eskenazi B. Change in paternity: a risk factor for pre-eclampsia in multiparas. Epidemiology 1996;7:240-4.

7 Robillard PY, Husley TC, Périanin J, Janky E, Miri EH, Papiernik E. Association of pregnancy-induced hypertension with duration of sexual cohabitation before conception. Lancet 1994;344:973-5.

8 Adams EM, Finlayson A. Familial aspects of pre-eclampsia and hypertension in pregnancy. Lancet 1961;ii:1375-8.

9 Sibai BM, Mercer B, Sarinoglu C. Severe pre-eclampsia in the second trimester: recurrence risk and long-term prognosis. Am J Obstet Gynecol 1991;165:1408-12.

10 Chesley LC, Cooper DW. Genetics of hypertension in pregnancy: possible single gene control of pre-eclampsia and eclampsia in the descendants of eclamptic women. Br J Obstet Gynaecol 1986;93:898-908.

11 Arngrimson R, Björnsson S, Geirsson RT, Björnsson H, Walker JJ, Snaedal G. Genetic and familial predisposition to eclampsia and pre-eclampsia in a defined population. $\mathrm{Br} J$ Obstet Gynaecol 1990;97:762-9.

12 Liston WA, Kilpatrick DC. Is genetic susceptibility to pre-eclampsia conferred by homozygosity for the same single recessive gene in mother and fetus? Br J Obstet Gynaecol 1991;98:1079-86.

13 Kilpatrick DC, Gibson F, Lingstone J, Liston WA. Pre-eclampsia is associated with HLA-DR4 sharing between mother and fetus. Tissue Antigens 1990;35:178-81

14 Arngrimson R, Purandare S, Connor M, Walker JJ, Björnsson S, Soubrie F, et al. Angiotensinogen: a candidate gene involved in pre-eclampsia? Nature Genetics 1993;4:114-5.

15 Folgerø T, Storbakk N, Torbergersen T, Øyan P. Mutations in mitochondrial transfer acid genes in pre-eclampsia. Am J Obstet Gynecol 1996;174:1626-30.

16 Lie RT, Wilcox A, Skjærven R. A population-based study of recurrence risks of birth defects. N Engl J Med 1994;331:1-4.

17 Engelman L. PLR-stepwise logistic regression. In: Dixon WJ, ed. BMDP statistical software. Berkeley: University of California Press, 1990.

18 Olson JM, Witte JS, Elston RC. Association within twin pairs for a dichotomous trait. Genet Epidemiol 1996;13:489-99.

19 Takimoto E, Ishida J, Sugivama F, Horiguchi H, Murakami K, Fukamizu A. Hypertension induced in pregnant mice by placental renin and maternal angiotensinogen. Science 1996;274:995-8.

20 Shanklin DR, Sibai BM. Ultrastructural aspects of pre-eclampsia. II. Mitochondrial changes. Am J Obstet Gynecol 1990;160:943-53.

21 Olsen J, Schmidt MM, Christensen K. Evaluation of nature-nurture impact on reproductive health using half-siblings. Epidemiology 1997;8: 6-11.

(Accepted 27 January 1998)

\section{Endpiece}

\section{Alternative definitions}

Eat: To perform successively (and successfully) the functions of mastication, humectation, and deglutition-in short, to eat.

Ambrose Bierce, The Cynic's Word Book (1906), subsequently titled The Devil's Dictionary 